\title{
Anthropometric measurements in the elderly: age and gender differences
}

\author{
Egle Perissinotto ${ }^{1 *}$, Claudia Pisent ${ }^{2}$, Giuseppe Sergi ${ }^{2}$, Francesco Grigoletto ${ }^{1}$ and Giuliano Enzi ${ }^{2}$ for the \\ ILSA Working Group $\dagger$ \\ ${ }^{1}$ Department of Environmental Medicine and Public Health, University of Padua, Italy \\ ${ }^{2}$ Department of Medical and Surgical Sciences, Division of Geriatrics, University of Padua, Italy
}

(Received 1 March 2001 - Revised 17 July 2001 - Accepted 3 September 2001)

\begin{abstract}
In clinical practice and epidemiological surveys, anthropometric measurements represent an important component of nutritional assessment in the elderly. The anthropometric standards derived from adult populations may not be appropriate for the elderly because of body composition changes occurring during ageing. Specific anthropometric reference data for the elderly are necessary. In the present study we investigated anthropometric characteristics and their relationship to gender and age in a cross-sectional sample of 3356 subjects, randomly selected from an elderly Italian population. In both sexes, weight and height significantly decreased with age while knee height did not. The BMI was significantly higher in women than in men $(27.6$ SD 5.7 v. 26.4 SD $3.7 ; P<0.001)$ and it was lower in the oldest than in the youngest subjects $(P<0 \cdot 05)$ of both genders. The 75th year of age was a turning point for BMI as for other anthropometric measurements. According to BMI values, the prevalence of malnutrition was lower than $5 \%$ in both genders, whereas obesity was shown to have a higher prevalence in women than in men $(28 \% v .16 \% ; P<0.001)$. Waist circumference and waist : hip ratio values were higher for the youngest men than for the oldest men $(P<0.05)$, whereas in women the waist : hip ratio values were higher in the oldest women, suggesting that visceral redistribution in old age predominantly affects females. In conclusion, in the elderly the oldest subjects showed a thinner body frame than the youngest of both genders, and there was a more marked fat redistribution in women.
\end{abstract}

\section{Anthropometry: Nutritional status: Elderly: Cross-sectional}

Anthropometric and nutritional characteristics are related to genetic, environmental, sociocultural conditions and to lifestyle, health and functional status. This makes it difficult to give a standard interpretation of their values. Anthropometry is an essential tool in geriatric nutritional assessment to evaluate underweight and obesity conditions, which are both important risk factors for severe diseases and disability in the elderly (Jensen \& Rogers, 1998; Visser et al. 1998).

An accurate evaluation of nutritional status should include an estimate of body compartments (fat-free mass and fat mass) by instrumental methods such as bioelectrical impedance analysis and dual X-ray absorptiometry (Enzi et al. 1997). Nevertheless, in clinical practice and in epidemiological surveys, body composition can be indirectly estimated by anthropometric measurements, which are non-invasive, easy and inexpensive to collect.

The ageing process involves modifications in nutritional and physiological status, such as a decrease in body weight and height (Dey et al. 1999), and a reduction in fat-free mass associated with an increase in fat mass. Moreover, a redistribution of adipose tissue occurs with accumulation in the trunk and visceral sites (Steen, 1988; Schwartz, 1998). Body composition changes occur differently in men and women and in the various phases of ageing, influencing anthropometry. Consequently, the anthropometric standard values derived from adult populations may not be applicable to the elderly.

Non-pathological factors affecting the distribution of anthropometric characteristics, such as age, gender and geographic area, should be taken into account. The WHO Expert Committee on Physical Status stressed the need for local gender- and age-specific reference values for the elderly (de Onis \& Habicht, 1996). In Europe, only a few anthropometric and nutritional studies have been carried out in the elderly (de Groot et al. 1996; Launer \& Harris, 1996;

\footnotetext{
Abbreviation: ILSA, Italian Longitudinal Study on Ageing.

* Corresponding author: Dr E. Perissinotto, fax +39049827 5392, email egle.perissinotto@unipd.it

$\dagger$ See the Appendix for a list of the ILSA Working Group members.
} 
Dey et al. 1999). The use of non-standardised methods for data collection and insufficient sample sizes make it difficult to compare reference values for clinical and epidemiological purposes.

Longitudinal studies are required to determine the magnitude of changes in anthropometric measures with ageing, but cross-sectional data have often been used, even though they might be affected by secular trend or cohort effect. Longitudinal and cross-sectional studies have, however, reported similar results on the effect of ageing on anthropometric and nutritional characteristics (Rea et al. 1997; Sorkin et al. 1999).

The principal aims of the present study were: (1) to provide distribution values for anthropometric characteristics based on a large cross-sectional sample randomly drawn from an elderly Italian population; (2) to quantify the prevalence of obesity and underweight conditions among the elderly in Italy; (3) to describe the age and gender differences of anthropometric characteristics in the elderly.

\section{Methods}

The present survey was based on anthropometric data derived from the Italian Longitudinal Study on Ageing (ILSA). The study had both a cross-sectional and a longitudinal component. Prevalence data obtained between March 1992 and June 1993 are considered here.

The design and methods of the study have been reported elsewhere (Maggi et al. 1994). Briefly, a gender- and agestratified sample of 5462 subjects aged 65-84 years was randomly drawn from the demographic lists of the registry office in eight municipalities: Genoa, Segrate (Milan), Selvazzano-Rubano (Padua), Impruneta (Florence), Fermo (Ascoli Piceno), Naples, Casamassima (Bari) and Catania. In order to oversample older people, an equal allocation strategy was used. The participation rate was $83 \%$ (4521 subjects). The study had two phases: a screening phase and a disease diagnosis phase. The screening phase of the study included a personal interview, a nurse visit and a clinical evaluation. The clinical evaluation included cognitive, psychological and physical examinations, anthropometric measurements and diet information. The second phase consisted of clinical confirmation of disease by a specialist. Details about diagnostic criteria and the health status of the sample have been described elsewhere (The ILSA Group, 1997).

Anthropometric measurements were collected from $74.2 \%(3356 / 4521)$ of the participants. The principal causes for missing data were, in decreasing order: refusal $(81 \%)$, death $(10 \%)$, upright incapability (4\%). The nonmeasurement rate depended on gender $(P<0.05)$ and age $(P<0 \cdot 01)$, being higher for the oldest women. Subjects who were measured and those who were not measured also differed regarding health status and disability. The prevalence rates of myocardial infarction, cardiac arrythmia and hypertension were higher $(P<0 \cdot 001)$ in subjects who were measured, while dementia, distal symmetric neuropathy of lower limbs and disability were more frequent $(P<0.001)$ among those not measured. The two groups did not significantly differ in the prevalence of diabetes, stroke, angina pectoris, congestive heart failure or peripheral artery disease.

\section{Anthropometric measures}

Anthropometric measurements were taken by trained personnel during clinical evaluation. Height and weight were measured with the subject barefooted and lightly dressed. Knee height was measured with a sliding caliper on the leg of the participant while seated and represented the distance from the sole of the foot to the anterior surface of the thigh, with the ankle and knee each flexed to a right angle, according to Chumlea et al. (1985). Body weight was measured on a balance beam platform scale (Salus, Milan, Italy) to the nearest $0 \cdot 1 \mathrm{~kg}$. Height was taken by a stadiometer (Salus) at head level to the nearest centimetre with the subject standing barefoot, with feet together. BMI was calculated (Quetelet, 1835). Three measurements of four skinfold thicknesses (triceps, subscapular, suprailiac, thigh) were taken by means of a calibrated caliper (precision $0.2 \mathrm{~mm}$; Harpenden skinfold caliper, John Bull British Indictor Ltd, UK) and averaged. The triceps skinfold was taken at the posterior mid-point between the acromion and the olecranon. The subscapular skinfold was measured just to the inferior angle of the scapula. The suprailiac skinfold was taken at the upper point of the iliac crest, the angle of inclination being $45^{\circ}$ towards the pubic symphysis. The thigh skinfold was measured at the medial point of the anterior surface of the thigh.

Circumferences were measured to the nearest centimetre using a flexible steel tape, with the subject standing. The abdominal circumference (waist) was measured at the end of expiration, by wrapping the tape at the level of the umbilicus. The hip circumference was measured at the maximum posterior protrusion of the buttocks. The waist: hip ratio was obtained by dividing the values of the two circumferences.

To evaluate the prevalence of undernutrition and obesity in our sample, we classified subjects on the basis of two cutoff points commonly used in clinical practice: BMI $<20 \mathrm{~kg} / \mathrm{m}^{2}$ was used to identify underweight subjects; $\mathrm{BMI} \geq 30 \mathrm{~kg} / \mathrm{m}^{2}$ was used to indicate obesity.

\section{Statistical analysis}

Anthropometric measurements were presented as mean value, standard deviation and centiles (5th, 10th, 25th, 50th, 75 th, 90th, 95th) by gender and age group (65-69, 70-74, $75-79,80-84$ years). For the whole sample, the means, standard deviations and prevalences were adjusted by weighting for the 1991 Italian population, to avoid bias derived from oversampling of the oldest subjects and different rates of response across strata (Kish, 1965). Variability was also expressed by the CV. Data were verified for their consistency. Missing data were not replaced by estimated values. The statistical analysis was performed by computation using the SAS Statistical Software Package version 6.12 (SAS Institute, Cary, NC, USA). The statistical significance of differences between genders was tested using Student's $t$ test $(\alpha=0 \cdot 05)$. The effect of age was investigated by ANOVA (SAS GLM 
procedure) and Tukey's multiple comparisons procedure $(\alpha=0 \cdot 05)$. Differences among prevalences were tested by the $\chi^{2}$ test and expressed as odds ratio. The association between age and anthropometric values, both considered as continuous variables, was evaluated using linear and quadratic regression models. To test the hypothesis of parallelism of regression lines we used a single regression model (SAS GLM procedure) containing dummy variables, to distinguish the groups being compared and verifying the interaction effect (Kleinbaum et al. 1998).

\section{Results}

Gender- and age-specific values (mean, standard deviation and centiles) are presented in the following analysis. Specific age and gender values neutralise selection bias deriving from different response rates in age and gender strata.

Men were taller than women (165.7 SD 6.7 v. 152.2 SD $7.5 \mathrm{~cm})$ and the difference in the total group, as in each age group, was statistically significant $(P<0 \cdot 001)$. The variability was similar (CV about $5 \%)$ in the two genders. Height was close to the normal distribution and showed a significant decrease with age in both sexes $(P<0.001)$. Older men were $2.7 \%$ shorter than younger men $(167 \cdot 1 \mathrm{SD}$
7.5 v. $162.7 \mathrm{SD} 7.2 \mathrm{~cm}$ ), while women had an age-related reduction in height of $4 \%(154.1 \mathrm{SD} 6.7 v .149 .3 \mathrm{SD} 7.0 \mathrm{~cm})$.

In women, height decreased at a constant rate with age, while in men Tukey's test indicated a significant difference between the first two and the second two age groups (Tables 1 and 2). For both genders, the linear regression model applied to crude data (Fig. 1) was more suitable for representing the age-related height decrease, showing the two linear equations as having the same mean decrement per year $(-0 \cdot 30 \mathrm{~cm} /$ year $)$.

Knee height was significantly higher in men than in women $(50.4$ SD 4.3 v. $45.8 \mathrm{SD} 3.8 \mathrm{~cm}$ ) but it did not vary significantly with age.

Tables 1 and 2 show that men were heavier than women in each age group $(P<0 \cdot 001)$. In both genders the mean weight significantly decreased with age $(P<0 \cdot 001)$. In men this age-related reduction represented $11 \%$ of the weight of younger men $(8 \mathrm{~kg})$, while in women this reduction was about $9 \%$ of the weight of younger women $(6 \mathrm{~kg})$. In both genders, mean values of weight were slightly higher than medians $(0.5-1 \mathrm{~kg}$ for males; $1-1.5 \mathrm{~kg}$ for females) showing a slight right asymmetry in the distribution, as has been described by other authors (Fanelli Kuczmarski et al. 2000). The variability in women (CV 20.5\%) was higher than in men (CV 14.7\%).

Table 1. Anthropometric indices in men (Italian Longitudinal Study on Ageing survey)

(Mean values, standard deviations and centiles)

\begin{tabular}{|c|c|c|c|c|c|c|c|c|c|c|c|}
\hline & \multirow[b]{2}{*}{ Age group } & \multirow[b]{2}{*}{$n$} & \multirow[b]{2}{*}{ Mean } & \multirow[b]{2}{*}{ SD } & \multicolumn{7}{|c|}{ Centile } \\
\hline & & & & & 5 & 10 & 25 & 50 & 75 & 90 & 95 \\
\hline \multirow[t]{5}{*}{ Weight (kg)†‡ } & $65-69$ & 466 & $74 \cdot 6^{\mathrm{a}}$ & $11 \cdot 2$ & 58 & 61 & 67 & 74 & 81 & 89 & 94 \\
\hline & $70-74$ & 451 & $74 \cdot 4^{\mathrm{a}}$ & 11.9 & 57 & 60 & 66 & 73 & 81 & 91 & 96 \\
\hline & $75-79$ & 392 & $69 \cdot 5^{\mathrm{b}}$ & $10 \cdot 7$ & 53 & 55 & 62 & 69 & 77 & 84 & 86 \\
\hline & $80-84$ & 365 & $66 \cdot 7^{\mathrm{C}}$ & $10 \cdot 7$ & 50 & 53 & 59 & 66 & 74 & 80 & 84 \\
\hline & All men & 1674 & $72 \cdot 6^{\star}$ & $10 \cdot 7^{\star}$ & 54 & 57 & 64 & 71 & 78 & 86 & 92 \\
\hline \multirow[t]{5}{*}{ Height $(\mathrm{cm}) \dagger \ddagger$} & $65-69$ & 469 & $167 \cdot 1^{\mathrm{a}}$ & $7 \cdot 5$ & 155 & 157 & 162 & 167 & 172 & 177 & 180 \\
\hline & $70-74$ & 457 & $166 \cdot 3^{\mathrm{a}}$ & $6 \cdot 4$ & 156 & 159 & 162 & 166 & 170 & 175 & 177 \\
\hline & $75-79$ & 407 & $163 \cdot 8^{\mathrm{b}}$ & $6 \cdot 6$ & 153 & 156 & 159 & 163 & 168 & 172 & 175 \\
\hline & $80-84$ & 384 & $162 \cdot 7^{\mathrm{C}}$ & $7 \cdot 2$ & 151 & 153 & 158 & 162 & 168 & 172 & 175 \\
\hline & All men & 1717 & $165 \cdot 7^{*}$ & $6 \cdot 7^{*}$ & 154 & 156 & 160 & 165 & 170 & 175 & 177 \\
\hline \multirow[t]{5}{*}{ BMI†‡ (kg/m²) } & $65-69$ & 465 & $26 \cdot 8^{\mathrm{a}}$ & $4 \cdot 2$ & $21 \cdot 2$ & $22 \cdot 3$ & $24 \cdot 3$ & $26 \cdot 6$ & $28 \cdot 7$ & $31 \cdot 2$ & $32 \cdot 5$ \\
\hline & $70-74$ & 448 & $27 \cdot 0^{\mathrm{a}}$ & 3.9 & $20 \cdot 8$ & $22 \cdot 2$ & $24 \cdot 3$ & $26 \cdot 5$ & $29 \cdot 1$ & $32 \cdot 0$ & 33.9 \\
\hline & $75-79$ & 391 & $26 \cdot 0^{\mathrm{b}}$ & $3 \cdot 6$ & $20 \cdot 4$ & 21.4 & $23 \cdot 4$ & $26 \cdot 0$ & $28 \cdot 2$ & $31 \cdot 2$ & $32 \cdot 4$ \\
\hline & $80-84$ & 362 & $25 \cdot 2^{\mathrm{C}}$ & 3.6 & $19 \cdot 6$ & $20 \cdot 8$ & $23 \cdot 0$ & $25 \cdot 0$ & $27 \cdot 4$ & $29 \cdot 6$ & $30 \cdot 8$ \\
\hline & All men & 1666 & $26 \cdot 4^{*}$ & $3 \cdot 7^{\star}$ & $20 \cdot 7$ & $21 \cdot 7$ & $23 \cdot 7$ & $26 \cdot 0$ & 28.4 & $31 \cdot 2$ & $32 \cdot 7$ \\
\hline \multirow[t]{5}{*}{ Waist circumference $(\mathrm{cm}) \ddagger$} & $65-69$ & 467 & $98 \cdot 1^{a}$ & $10 \cdot 2$ & 82 & 85 & 92 & 98 & 104 & 111 & 116 \\
\hline & $70-74$ & 458 & $98 \cdot 5^{\mathrm{a}}$ & $11 \cdot 1$ & 81 & 85 & 92 & 98 & 105 & 112 & 117 \\
\hline & $75-79$ & 409 & $96 \cdot 4^{b}$ & $10 \cdot 7$ & 79 & 83 & 89 & 97 & 103 & 110 & 114 \\
\hline & $80-84$ & 395 & $94 \cdot 8^{\mathrm{C}}$ & $11 \cdot 3$ & 77 & 82 & 88 & 95 & 102 & 108 & 112 \\
\hline & All men & 1729 & $97 \cdot 5^{\star}$ & $9 \cdot 9^{*}$ & 80 & 84 & 90 & 97 & 104 & 110 & 115 \\
\hline \multirow[t]{5}{*}{ Hip circumference $(\mathrm{cm}) \dagger \ddagger$} & $65-69$ & 467 & $100 \cdot 6^{\mathrm{a}}$ & $8 \cdot 4$ & 89 & 92 & 96 & 100 & 105 & 111 & 115 \\
\hline & $70-74$ & 458 & $101 \cdot 0^{\mathrm{a}}$ & $9 \cdot 6$ & 89 & 92 & 96 & 101 & 106 & 112 & 117 \\
\hline & $75-79$ & 409 & $99 \cdot 6^{\mathrm{a}}$ & 8.9 & 87 & 90 & 94 & 100 & 105 & 110 & 115 \\
\hline & $80-84$ & 387 & $98 \cdot 3^{\mathrm{b}}$ & $9 \cdot 6$ & 86 & 89 & 94 & 98 & 104 & 109 & 112 \\
\hline & All men & 1721 & $100 \cdot 2^{*}$ & $8 \cdot 3^{*}$ & 88 & 91 & 95 & 100 & 105 & 110 & 115 \\
\hline \multirow[t]{5}{*}{ Waist:hip ratio†‡ } & $65-69$ & 466 & $0.97^{\mathrm{a}}$ & 0.05 & 0.88 & 0.90 & 0.93 & 0.97 & $1 \cdot 01$ & 1.04 & 1.06 \\
\hline & $70-74$ & 456 & $0.97^{\mathrm{a}}$ & 0.06 & 0.88 & 0.90 & 0.94 & 0.97 & 1.00 & 1.04 & 1.07 \\
\hline & $75-79$ & 404 & $0.96^{b}$ & 0.05 & 0.87 & 0.90 & 0.93 & 0.96 & 1.00 & 1.03 & 1.05 \\
\hline & $80-84$ & 384 & $0.95^{\mathrm{c}}$ & 0.06 & 0.86 & 0.88 & 0.92 & 0.95 & 0.99 & 1.02 & 1.04 \\
\hline & All men & 1710 & $0.97^{*}$ & $0.05^{\star}$ & 0.87 & 0.89 & 0.93 & 0.96 & 1.00 & 1.03 & 1.05 \\
\hline
\end{tabular}

${ }^{a, b, c}$ For the same variable, mean values with unlike superscript letters were significantly different $(P<0 \cdot 05)$.

* Weighted mean and standard deviation values.

† Statistically significant difference of mean values between genders (Student's $t$ test).

¥ Statistically significant difference of mean values across age groups (ANOVA). 


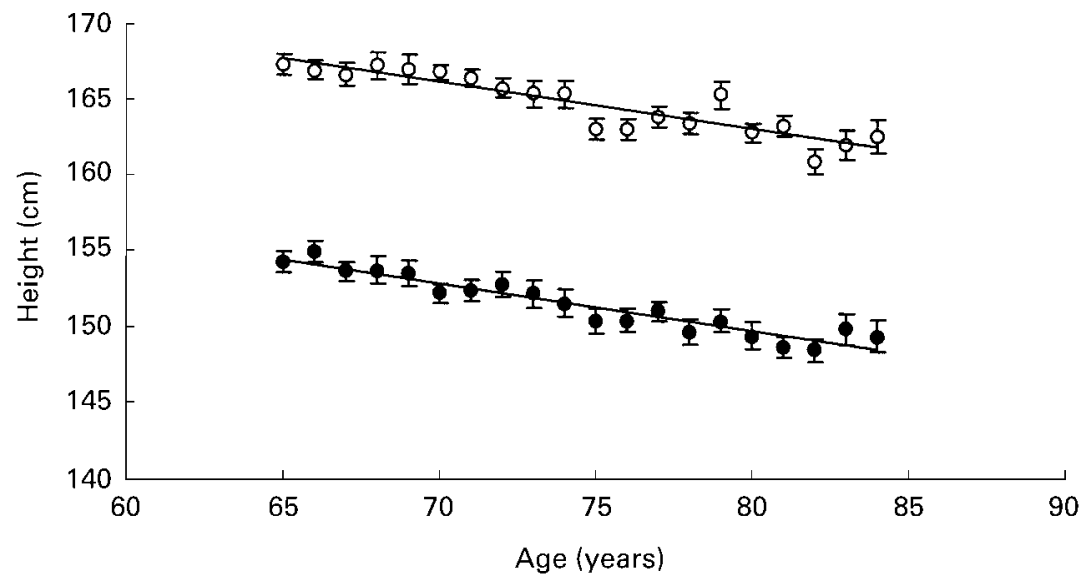

Fig. 1. Height by age (1-year age groups) and gender: men (O) $y=-0.30$ $x+187.2$; women $(\bullet) y=-0.30 x+174.2$. Points are means with their standard errors represented by vertical bars.

In examining the trend of weight by age, the rate of decrease was found to be more evident for men than for women, showing a more consistent loss of fat-free mass (Gallagher et al. 1997). In men, Tukey's multiple comparisons test showed a significant difference between the mean values of weight of the three oldest age groups of 5-year periods taken two-by-two, while in women only the first two age groups were significantly heavier than the second two age groups. In both genders, Tukey's test indicated the 75th year of age as a starting point for significant weight loss (Tables 1 and 2). Linear regression between weight and age is shown in Fig. 2. The slopes of the

Table 2. Anthropometric indices in women (Italian Longitudinal Study on Ageing survey)

(Mean values, standard deviations and centiles)

\begin{tabular}{|c|c|c|c|c|c|c|c|c|c|c|c|}
\hline & \multirow[b]{2}{*}{ Age group } & \multirow[b]{2}{*}{$n$} & \multirow[b]{2}{*}{ Mean } & \multirow[b]{2}{*}{ SD } & \multicolumn{7}{|c|}{ Centile } \\
\hline & & & & & 5 & 10 & 25 & 50 & 75 & 90 & 95 \\
\hline \multirow[t]{5}{*}{ Weight (kg)†‡ } & $65-69$ & 418 & $66 \cdot 2^{\mathrm{a}}$ & $12 \cdot 0$ & 49 & 52 & 58 & 65 & 73 & 81 & 90 \\
\hline & $70-74$ & 370 & $64 \cdot 8^{\mathrm{a}}$ & $12 \cdot 5$ & 46 & 51 & 55 & 63 & 73 & 81 & 85 \\
\hline & $75-79$ & 361 & $61 \cdot 1^{\mathrm{b}}$ & $10 \cdot 6$ & 45 & 48 & 54 & 61 & 68 & 76 & 79 \\
\hline & $80-84$ & 313 & $60 \cdot 0^{\mathrm{b}}$ & $11 \cdot 7$ & 42 & 46 & 52 & 59 & 67 & 77 & 80 \\
\hline & All women & 1462 & $63 \cdot 8^{*}$ & $13 \cdot 1^{*}$ & 45 & 49 & 55 & 62 & 71 & 79 & 84 \\
\hline \multirow[t]{5}{*}{ Height (cm)†‡ } & $65-69$ & 436 & $154 \cdot 1^{\mathrm{a}}$ & $6 \cdot 7$ & 143 & 146 & 150 & 154 & 159 & 163 & 165 \\
\hline & $70-74$ & 379 & $152 \cdot 3^{b}$ & 6.5 & 142 & 144 & 148 & 152 & 157 & 160 & 163 \\
\hline & $75-79$ & 373 & $150 \cdot 6^{c}$ & $6 \cdot 4$ & 141 & 143 & 146 & 151 & 155 & 159 & 161 \\
\hline & $80-84$ & 329 & $149 \cdot 3^{d}$ & 7.00 & 138 & 141 & 144 & 149 & 154 & 158 & 160 \\
\hline & All women & 1517 & $152 \cdot 2^{*}$ & $7 \cdot 5^{*}$ & 141 & 143 & 147 & 152 & 156 & 160 & 163 \\
\hline \multirow[t]{5}{*}{ BMI†‡ (kg/m²) } & $65-69$ & 417 & $28 \cdot 0^{\mathrm{a}}$ & $5 \cdot 2$ & $21 \cdot 0$ & $22 \cdot 1$ & $24 \cdot 4$ & $27 \cdot 3$ & $30 \cdot 6$ & $35 \cdot 2$ & $37 \cdot 4$ \\
\hline & $70-74$ & 368 & $27 \cdot 9^{a}$ & $5 \cdot 0$ & $20 \cdot 4$ & $21 \cdot 9$ & $24 \cdot 3$ & $27 \cdot 4$ & $31 \cdot 2$ & $33 \cdot \overline{8}$ & $36 \cdot 0$ \\
\hline & $75-79$ & 361 & $27 \cdot 1^{\mathrm{b}}$ & $5 \cdot 2$ & $20 \cdot 0$ & $21 \cdot 2$ & $23 \cdot 7$ & 26.5 & 29.9 & $32 \cdot 4$ & 34.4 \\
\hline & $80-84$ & 308 & $27 \cdot 1^{\mathrm{b}}$ & $5 \cdot 8$ & $18 \cdot 9$ & $20 \cdot 4$ & $23 \cdot 5$ & $26 \cdot 7$ & $30 \cdot 1$ & $33 \cdot 4$ & $35 \cdot 6$ \\
\hline & All women & 1454 & $27 \cdot 6^{\star}$ & $5 \cdot 7^{\star}$ & $20 \cdot 1$ & 21.5 & 24 & 27 & 30 & 34 & $36 \cdot 4$ \\
\hline \multirow[t]{5}{*}{ Waist circumference (cm) } & $65-69$ & 440 & $97 \cdot 2^{\mathrm{a}}$ & $13 \cdot 2$ & $75 \cdot 5$ & 80 & 89 & 97 & $105 \cdot 5$ & 114 & 121.5 \\
\hline & $70-74$ & 389 & $97 \cdot 4^{\mathrm{a}}$ & $12 \cdot 9$ & 76 & 80 & 89 & 98 & 106 & 114 & 119 \\
\hline & $75-79$ & 375 & $96 \cdot 2^{\mathrm{a}}$ & $12 \cdot 4$ & 75 & 80 & 88 & 96 & 104 & 112 & 117 \\
\hline & $80-84$ & 346 & $96 \cdot 5^{\mathrm{a}}$ & $12 \cdot 8$ & 75 & 80 & 89 & 97 & 105 & 113 & 117 \\
\hline & All women & 1550 & $96 \cdot 9^{\star}$ & $14 \cdot 1^{*}$ & 75 & 80 & 88 & 97 & 106 & 113 & 118 \\
\hline \multirow[t]{5}{*}{ Hip circumference $(\mathrm{cm}) \dagger \ddagger$} & $65-69$ & 440 & $104 \cdot 5^{\mathrm{a}}$ & 11.5 & 88 & 91 & 97 & 103 & 110 & 119 & 125 \\
\hline & $70-74$ & 390 & $104 \cdot 0^{\mathrm{a}}$ & $10 \cdot 7$ & 88 & 92 & 96 & 103 & 111 & 117.5 & 123 \\
\hline & $75-79$ & 373 & $102 \cdot 3^{b}$ & $10 \cdot 4$ & 87 & 90 & 96 & 101 & 109 & 116 & 122 \\
\hline & $80-84$ & 347 & $101 \cdot 5^{b}$ & 11.4 & 85 & 89 & 95 & 102 & 108 & 116 & 120 \\
\hline & All women & 1550 & $103 \cdot 4^{*}$ & $12 \cdot 1^{*}$ & 87 & 90 & 96 & 102 & 110 & 117 & 123 \\
\hline \multirow[t]{5}{*}{ Waist:hip ratio† } & $65-69$ & 438 & $0.93^{a}$ & 0.06 & 0.80 & 0.83 & 0.88 & 0.93 & 0.97 & 1.01 & 1.04 \\
\hline & $70-74$ & 389 & $0.93^{a}$ & 0.07 & 0.81 & 0.84 & 0.89 & 0.93 & 0.98 & 1.02 & 1.04 \\
\hline & $75-79$ & 372 & $0.94^{\mathrm{a}}$ & 0.07 & 0.82 & 0.85 & 0.90 & 0.93 & 0.98 & 1.02 & 1.04 \\
\hline & $80-84$ & 345 & $0.95^{\mathrm{b}}$ & 0.06 & 0.83 & 0.86 & 0.90 & 0.95 & 0.99 & 1.03 & 1.05 \\
\hline & All women & 1544 & $0.94^{*}$ & $0.08^{*}$ & 0.81 & 0.84 & 0.89 & 0.94 & 0.98 & 1.02 & 1.04 \\
\hline
\end{tabular}

${ }_{a, b, c, d}$ For the same variable, mean values with unlike superscript letters were significantly different $(P<0.05)$.

${ }^{*}$ Weighted mean and standard deviation values.

†Statistically significant difference of mean values between genders (Student's $t$ test).

$\ddagger$ Statistically significant difference of mean values across age groups (ANOVA). 


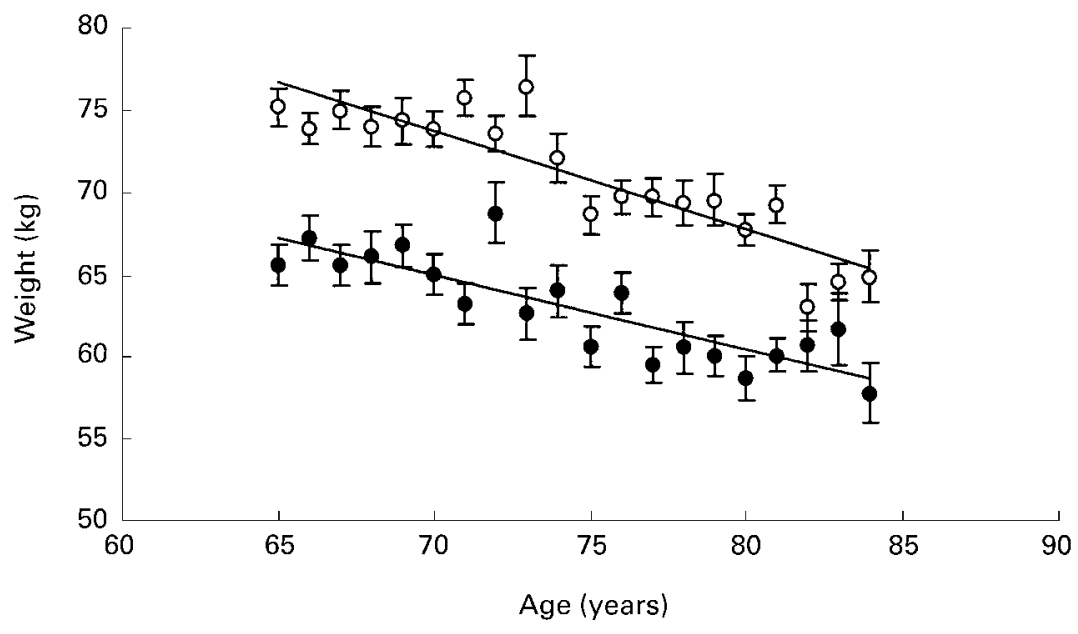

Fig. 2. Weight by age (1-year age groups) and gender: men $(\bigcirc) y=-0.59$ $x+115 \cdot 2$; women $(\bullet) y=-0.44 x+95.7$. Points are means with their standard errors represented by vertical bars.

regression lines seem to indicate a greater rate of weight decrease in men $(-0.59 \mathrm{~kg} / \mathrm{year})$ than in women $(-0.44 \mathrm{~kg} /$ year), but the difference was not significant $(P=0.08)$, perhaps owing to the high variability of weight. The quadratic regression model, applied to crude data, provided a slightly better fit of the distribution than the linear model in the men only, indicating an increasing rate of weight loss with age.

The mean BMI was significantly higher in women than in men in the whole group $\left(27.6 \mathrm{SD} 5.7 v .26 \cdot 4 \mathrm{SD} 3.7 \mathrm{~kg} / \mathrm{m}^{2}\right)$ and in each age class. This index decreased significantly with age in both genders, showing a reduction of about 1 unit over two decades. The slight asymmetric distribution of the BMI reflects the asymmetry reported for weight. Moreover, women presented a higher variability (CV $20.7 \%$ ) than men (CV $14.0 \%)$, reflecting the higher variability in weight.

The BMI reduction was regular in men only (Fig. 3). Tukey's test showed that in men the decrease became statistically significant after the 75 th year of age, while in women, after a significant change at about the same age, the mean of the index did not change. The 75th year of age was a turning point in age-related changes for BMI as well as for other anthropometric measurements.

The adjusted prevalence of underweight was $3.6 \%$ in the whole sample and higher in women $(4.3 \%)$ than in men $(2.7 \%)$. The higher risk for women to be underweight was quantified by odds ratio $1.5(95 \%$ CI $1 \cdot 0,2 \cdot 1)$.

Obesity was a diffuse condition among the elderly, with an overall adjusted prevalence of $22 \cdot 3 \%$. The problem was more frequent in women $(27.9 \%)$ than in men $(15.5 \%)$ (Fig. 4). The higher risk of obesity for women was evaluated by odds ratio $2 \cdot 2(95 \%$ CI $1 \cdot 9,2 \cdot 6)$.

The mean value of waist circumference did not differ significantly between the two genders $(97.5$ SD 9.9 in men $v$. $96.9 \mathrm{SD} 14.1 \mathrm{~cm}$ in women), and decreased significantly with age, in men only. Differing from waist circumference, the mean value of hip circumference was significantly higher in women than in men (103.4 SD $12 \cdot 1 v .100 \cdot 2$ SD $8.3 \mathrm{~cm}$ ), reflecting the thicker gluteal subcutaneous fat in

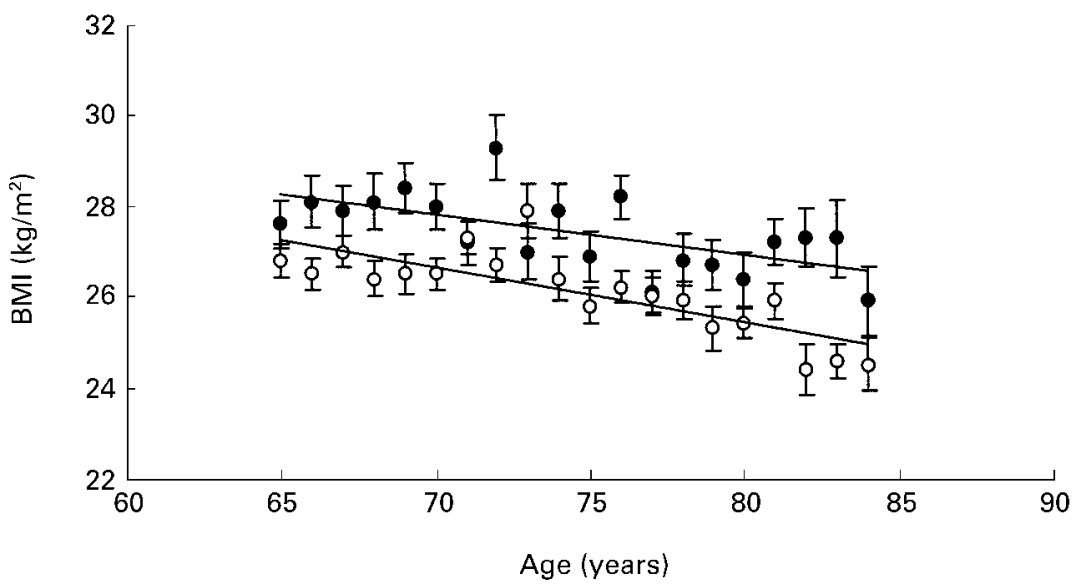

Fig. 3. BMI by age (1-year age groups) and gender: men (O) $y=-0 \cdot 12 x+35 \cdot 3$; women $(\bullet) y=-0.09 x+33.9$. Points are means with their standard errors represented by vertical bars. 


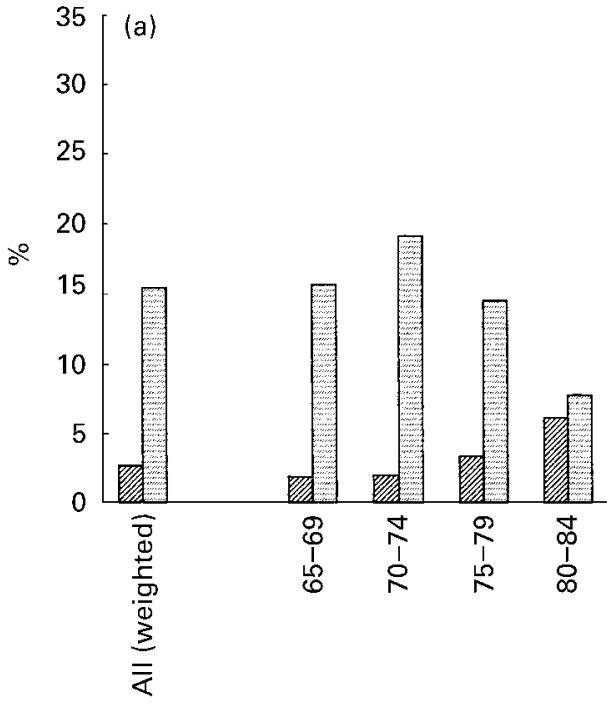

Age (years)

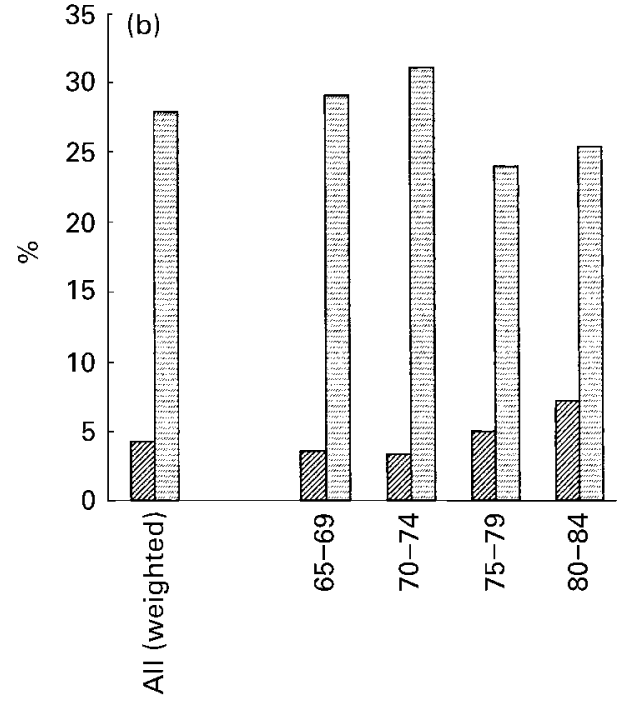

Age (years)

Fig. 4. Underweight $\left(\mathrm{BMI}<20 \mathrm{~kg} / \mathrm{m}^{2} ; 囚\right)$; and obesity (BMI $\geq 30 \mathrm{~kg} / \mathrm{m}^{2}$; 目) prevalences by gender (men (a) and women (b)) for 5 -year age categories.

women. The hip circumference decreased significantly with age in both sexes.

The mean waist : hip ratio was significantly higher in men (0.97 SD 0.05 v. 0.94 SD 0.08), where it showed a significant age-related reduction, while in women this rate slightly but significantly increased with age.

The mean values of the four skinfold thicknesses were significantly $(P<0.001)$ higher in women than in men (triceps 20.5 SD 8.3 v. 12.3 SD $5.8 \mathrm{~mm}$; subscapular $19.3 \mathrm{SD}$ 9.1 v. $16.7 \mathrm{SD} 6.1 \mathrm{~mm}$; suprailiac $19.8 \mathrm{SD} 9.7$ v. $14.0 \mathrm{SD}$ $6.6 \mathrm{~mm}$; thigh $24.3 \mathrm{SD} 10.6 \mathrm{v} .14 .3 \mathrm{sD} 6.7 \mathrm{~mm})$. For these variables, in both genders the age-related reduction (data not shown) was statistically significant $(P<0 \cdot 01)$.

\section{Discussion}

In the present cross-sectional study we investigated anthropometric measurements in an elderly population and compared our findings with those provided by similar studies. The lack of anthropometric cross-sectional surveys in Italian populations limits the comparison of our genderand age-specific results with those produced by other studies. Between 1988 and 1993 a European multicentre study (Euronut Seneca Study) on nutrition and anthropometric characteristics was carried out on a sample of 2332 elderly subjects born between 1913 and 1918 in twelve European countries (de Groot et al. 1992, 1996). For the same age group, our sample somatotype was similar to that described by the Seneca Study (Table 3) for Italian men and women (de Groot et al. 1991). The comparison between the characteristics of our subjects and those of European populations confirms that the Italian elderly population is in the lower mid-section of the distribution (Table 3). With reference to a typical Mediterranean somatotype, our

Table 3. Weight, height and BMI by gender, in subjects 70-75 years of age. Comparison of results of the Italian Longitudinal Study on Ageing (ILSA) with the values provided by de Groot et al. (1991) for selected European sites

(Mean values and standard deviations)

\begin{tabular}{|c|c|c|c|c|c|c|c|c|c|c|c|c|}
\hline \multirow{3}{*}{ Country } & \multicolumn{6}{|c|}{ Men } & \multicolumn{6}{|c|}{ Women } \\
\hline & \multicolumn{2}{|c|}{ Weight (kg) } & \multicolumn{2}{|c|}{ Height (m) } & \multicolumn{2}{|c|}{ BMI $\left(\mathrm{kg} / \mathrm{m}^{2}\right)$} & \multicolumn{2}{|c|}{ Weight (kg) } & \multicolumn{2}{|c|}{ Height (m) } & \multicolumn{2}{|c|}{ BMI $\left(\mathrm{kg} / \mathrm{m}^{2}\right)$} \\
\hline & Mean & SD & Mean & SD & Mean & SD & Mean & SD & Mean & SD & Mean & SD \\
\hline Denmark (Roskilde) & $75 \cdot 0$ & $10 \cdot 4$ & 1.71 & 0.07 & 25.5 & $3 \cdot 2$ & 64.5 & $12 \cdot 4$ & 1.59 & 0.05 & $25 \cdot 2$ & 4.7 \\
\hline The Netherlands (Culemborg) & $78 \cdot 2$ & $10 \cdot 7$ & 1.73 & 0.08 & $26 \cdot 1$ & 3.0 & 71.4 & 11.4 & 1.60 & 0.06 & $27 \cdot 6$ & $4 \cdot 2$ \\
\hline Belgium (Hamme) & $71 \cdot 4$ & $10 \cdot 5$ & 1.69 & 0.07 & $25 \cdot 2$ & $3 \cdot 3$ & $68 \cdot 2$ & $10 \cdot 3$ & 1.53 & 0.06 & $28 \cdot 3$ & $4 \cdot 2$ \\
\hline France (Haguenau) & 77.9 & $12 \cdot 7$ & 1.68 & 0.06 & $27 \cdot 1$ & 3.6 & $68 \cdot 1$ & 14.4 & 1.57 & 0.06 & $27 \cdot 6$ & $3 \cdot 6$ \\
\hline Greece (Markopoulo) & $76 \cdot 8$ & $12 \cdot 7$ & 1.67 & 0.06 & 27.5 & $4 \cdot 3$ & $69 \cdot 3$ & $10 \cdot 3$ & 1.52 & 0.06 & $29 \cdot 7$ & $2 \cdot 6$ \\
\hline Spain (Bentazos) & $77 \cdot 2$ & $10 \cdot 6$ & 1.62 & 0.08 & $27 \cdot 7$ & 3.6 & 65.5 & 11.2 & 1.49 & 0.06 & $28 \cdot 6$ & 4.4 \\
\hline Portugal (Vila Franca de Xira) & $70 \cdot 6$ & $11 \cdot 2$ & 1.61 & 0.06 & $27 \cdot 0$ & 3.6 & $60 \cdot 2$ & $11 \cdot 0$ & 1.46 & 0.05 & $27 \cdot 5$ & 4.5 \\
\hline Italy (Padua) & $73 \cdot 6$ & $10 \cdot 0$ & 1.67 & 0.06 & $26 \cdot 1$ & 3.5 & $61 \cdot 0$ & $10 \cdot 9$ & 1.56 & 0.06 & 24.9 & $4 \cdot 2$ \\
\hline $\begin{array}{l}\text { Italy (Fara Sabina, Magliano Sabina, } \\
\text { Poggio Mirteto) }\end{array}$ & $77 \cdot 6$ & $15 \cdot 2$ & $1 \cdot 60$ & 0.05 & $30 \cdot 3$ & $5 \cdot 2$ & $68 \cdot 2$ & $13 \cdot 4$ & 1.49 & 0.06 & $30 \cdot 5$ & $(5 \cdot 1)$ \\
\hline ILSA & 74.4 & 11.9 & 1.66 & 0.06 & $27 \cdot 0$ & $3 \cdot 9$ & $64 \cdot 8$ & $12 \cdot 5$ & 1.52 & 0.06 & $27 \cdot 9$ & $5 \cdot 0$ \\
\hline
\end{tabular}


subjects are smaller, and the women, in relation to height, are heavier than Northern European subjects. Further comparisons with data provided by other European studies confirmed these findings (Delarue et al. 1994; Bannerman et al. 1997). Considering American anthropometric data from the third National Health and Nutrition Examination Survey (NHANES III), our subjects appeared shorter and the women, adjusting for height, heavier than the Americans (Fanelli Kuczmarski et al. 2000).

In considering anthropometric indicators, it is crucial to establish the pattern of their relationship with selected characterising factors such as age and gender. Even though derived from a cross-sectional study, the highlighted patterns of gender- and age-related changes in weight and stature seem to correspond to those described in some longitudinal studies (de Groot et al. 1996; Dey et al. 1999; Sorkin et al. 1999).

In our 65-84-year sample, age was inversely and significantly associated with ten out of twelve anthropometric indices in both genders with the exception of waist circumference in women and knee height in both men and women. The mean values of all anthropometric measurements significantly differed between gender, except for waist circumference. Weight, height, knee height and waist : hip ratio were higher in men; BMI, hip circumference, thigh circumference and skinfold thickness were greater in women.

\section{Height}

The remarkable entity of height decrease observed in our present study $(2-3 \mathrm{~cm} /$ decade $)$ is comparable with the results of other Italian and international surveys: the Euronut Seneca Study reported a height decrease in both men and women of $1-2 \mathrm{~cm}$ in 4 years, i.e. $2 \cdot 5-5 \mathrm{~cm} /$ decade. For Swedish elderly, Dey et al. (1999) quantified a mean decrement of $4-5 \mathrm{~cm}$ over 25 years. Baumgartner et al. $(1995 b)$ reported a decrease of $0.5-1.5 \mathrm{~cm} /$ decade.

We considered the possible role of a secular trend in the remarkable height decrease observed in our study. As many authors assert, in developed countries a positive trend in stature began about the second part of the nineteenth century and was more evident for men than for women (Malina, 1990; Meadows Janz \& Janz, 1999). This occurred also in Italy, where the mean stature of young males called up for the army in 1928 and 1943 (corresponding to our oldest and youngest age group called up by year) differed by $1.5 \mathrm{~cm}$ (ISTAT, 1986). Mean stature between our youngest and oldest men differed by $4-5 \mathrm{~cm}$, a decrease three times higher than that potentially due to the secular trend. It should be noted that the positive secular trend was more evident in distal lower limb bones and consequently in knee height (Meadows Janz \& Janz, 1999); in our data, knee height did not correlate with age. If the youngest subjects were taller than the oldest subjects because of the positive secular trend, the same relationship would be expected in knee height, but this was not the case. We conclude that the possible effect of the secular positive trend was not the sole cause of the difference in stature of the youngest and oldest subjects observed in our present study.

The above considerations justify the conclusion that our oldest subjects had a basal body height similar to the youngest subjects and that this decreased with age principally because of spinal deformity and thinning of the intervertebral discs.

\section{Weight}

In contrast to height, weight may voluntarily or involuntarily fluctuate during adulthood and older life. This makes it more difficult to investigate the role of weight in health by cross-sectional data. Our results indicate a negative association between weight and age in both sexes. This trend may be a consequence of a selection bias due to the death of overweight or obese subjects. However, whole weight distributions of all age groups shifted towards lower values (Tables 1 and 2). The decrease with regard to 6569-year-old subjects was about $14 \%$ for the 5th centile $v$. about $11 \%$ for the 95 th centile.

Furthermore, a cohort effect might have biased our results. There could be a confounding height effect if younger subjects were the tallest (height and weight being positively correlated), but, as previously explained, this was not so. A further matter could be that overweight may be less prevalent in an older population who had lived through a double war experience, but that argument is more complex. In spite of these considerations, longitudinal studies support an age-related weight reduction (Going et al. 1995; de Groot et al. 1996; Dey et al. 1999). Examining longitudinal changes for a sample of 70-year-olds in Sweden, Dey et al. (1999) found a mean decrement of the same order as ours $(-0.4 \mathrm{~kg} /$ year $)$ over a 20 -year period.

\section{$B M I$}

Among all anthropometric measurements, the BMI represents the easier and most frequently used index to identify subjects at risk for under- or overnutrition. Many authors agree in considering this index a poor indicator of risk in the elderly (Harris et al. 1988; Visser et al. 1994, Allison et al. 1997; Seidell \& Visscher, 2000), because it does not reflect regional distribution of fat or any change in fat distribution in the elderly. The value of the BMI is generally considered to be as a measurement of fatness, while it also gives information about fat-free mass. In the elderly, fat mass increases whereas fat-free mass decreases (Steen, 1988). The same adult BMI value corresponds to a more fatty body composition in the elderly. Thus the BMI has to be differently interpreted for elderly subjects. Undernutrition and obesity BMI thresholds in the elderly are currently being discussed. It is questionable whether cut-off values for obesity should be higher in the elderly, as body weight associated with minimal mortality increases with age (Allison et al. 1997) and the relative risk of mortality associated with a higher BMI decreases with age (Stevens et al. 1998). On the other side of the scale, undernutrition is a well-known predictor of mortality (Visscher et al. 2000), and modification of cut-off values to identify patients at nutritional risk has been suggested (Corish et al. 2000).

Some data on the BMI of the Italian population have been produced by the National Research Council through a cross-sectional multicentre study carried out in 1984 on 
65-95-year-old subjects (Melchionda et al. 1990). Comparing BMI between the ILSA and the National Research Council study, similar values were found for the 50 th centile $\left(26.0 \mathrm{~kg} / \mathrm{m}^{2}\right.$ in both studies for men; $27.0 \mathrm{v}$. $27.7 \mathrm{~kg} / \mathrm{m}^{2}$ for women) of the total sample distributions. Differences between the results of the two studies were found for all the centiles related to women in the 6574-year age group, for which ILSA values were approximately 1 unit smaller than National Research Council values. Given the more recent collection of the ILSA data, the lower BMI values reported by ILSA for the youngest women might reflect a change of the cultural model in controlling nutritional habits. As compared with NHANES III data (Fanelli Kuczmarski et al. 2000) our obesity prevalence was similar.

In both genders the prevalence of obesity (Fig. 4) decreased with age, while the prevalence of underweight increased; this is in accordance with the pattern described by other authors for different populations (Launer \& Harris, 1996). In our data, a BMI of $30 \mathrm{~kg} / \mathrm{m}^{2}$ corresponded to different centiles in the two sexes: 85 th for men and 75 th for women. Relating the concept of 'normality' (i.e. nonobesity) to the most frequent values in the population, it seems that this cut-off value could overestimate the obesity in the Italian population, particularly in women. Obesity should probably be identified by different cut-off points for men and women.

In our male and female BMI distributions, a BMI of $20 \mathrm{~kg} / \mathrm{m}^{2}$ approximately corresponded to the 5 th centile. This could provide a useful estimate of an underweight condition in the Italian elderly. Whereas for adults a lower cut-off for BMI $\left(<18.5 \mathrm{~kg} / \mathrm{m}^{2}\right)$ is considered (WHO, 1995), the criterion of BMI $<20 \mathrm{~kg} / \mathrm{m}^{2}$ is widely adopted in geriatric clinical practice (Mattila et al. 1986; McWhirter \& Pennington, 1994; Launer \& Harris, 1996; Corish et al. 2000). A lower cut-off value might be inappropriate; because of the higher BMI values amongst older populations, a more severe degree of undernutrition may be selected. However, early detection is more important of those who may be at nutritional risk.

\section{Waist:hip ratio and waist circumference}

Metabolic changes occur in the elderly: a lean tissue loss, a decrease in total body water and a more central distribution of adiposity (Enzi et al. 1986; Chumlea \& Baumgartner, 1989; Schwartz, 1998). The increase in intra-abdominal fat accumulation occurs in both genders, first in men then in women, where it occurs in the postmenopausal period (Enzi et al. 1986; Chumlea \& Baumgartner, 1989; Kotani et al. 1994). In the adult population, the waist:hip ratio (Baumgartner et al. 1995a) and waist circumference (Pouliot et al. 1994; Han et al. 1995; Lean et al. 1995; Seidell et al. 2001) are commonly used as indicators of visceral adiposity. Reference data regarding the waist:hip ratio and waist circumference are not available for the Italian elderly, and other cross-sectional and longitudinal studies have not included subjects older than 75 years of age. Our findings allow consideration of a later phase of physiological ageing.

In the present study, elderly men showed an age-related decrease in waist circumference, hip circumference, waist:hip ratio and all skinfold thicknesses. This may suggest that in men the fat increase with accumulation at visceral sites occurs predominatly in middle age, while the most remarkable phenomenon in the elderly is the reduction in body frame, fat and muscle mass.

Anthropometric variations pointed out for women indicate a different pattern in the relationship between fat distribution and age. Being in a late postmenopausal period, our women presented a morphological evolution markedly reflecting the lack of estrogenic effects. In contrast to increases in anthropometric values (waist and hip circumferences, BMI, weight) found in younger postmenopausal women (Den Tonkelaar et al. 1989; Schwartz, 1998) we found a general anthropometric decrement with the only increase in waist:hip ratio, mainly due to the decrease in hip circumference, which has also been reported by other studies (de Groot et al. 1996). Our findings are consistent with the hypothesis of an increase in visceral adiposity in postmenopausal women, highlighted by many studies, most of which are based on computed tomography scans (Kotani et al. 1994; Zamboni et al. 1997). Despite abdominal skinfolds becoming thinner with age, waist circumference does not vary, suggesting an increase in visceral fat.

In younger populations the waist:hip ratio, usually employed to distinguish visceral from subcutaneous obesity, is an independent predictor of $\mathrm{CHD}$ and metabolic disturbances. Contrary to the men, our women had mean values of the waist:hip ratio commonly considered to be associated with an increased risk of mortality (Heymsfield et al. 1998) in the young. Moreover, many authors consider waist circumference to be better correlated with abdominal visceral adipose tissue, as a potentially 'atherogenic' metabolic disease source, than the waist: hip ratio (Pouliot et al. 1994), which depends both on visceral fatness and muscle mass quantified by hip circumference (Seidell et al. 1997). This issue is still under debate (Molarius \& Seidell, 1998). On the basis of defined upper levels of waist circumference $(88 \mathrm{~cm}$ for women and $102 \mathrm{~cm}$ for men) suggested by Lean et al. (1995), over $75 \%$ of our women could be considered obese, in relation to cardiovascular risk. The analysis of our longitudinal data could clarify whether such high mean values of the waist: hip ratio and waist circumference in elderly women are associated with a higher risk of morbidity and mortality.

The present study has some limits. First of all, it was a cross-sectional study and therefore we cannot exclude survival or birth-cohort bias or discount temporal or cohort effects. The cross-sectional part of the study did not allow evaluation of individual changes for anthropometric characteristics. As a consequence, we dealt with the relationship of age with measurements and not with changes in measurements. Nevertheless, our results are largely consistent with longitudinal findings. Second, with regard to health status of subjects who were measured and those who were not measured, differences in the prevalence of disease were generally higher for the subjects with anthropometric measures, mainly for myocardial infarction, arrhythmia and peripheral neuropathy. We do not ascribe this difference to major illness of participating subjects. Health assessment was mostly indirect for non-participating subjects, and as a 
consequence, diseases could be underreported. On the other hand, participating patients, who screened positive for some diseases, underwent assessment by a specialist, and diagnoses were more accurately made. Among diseases related to nutritional status, diabetes had the same prevalence $(13 \%)$ among subjects who were measured and those who were not measured.

The higher level of disability among those not measured was evaluated on a small number of subjects (less than $10 \%$ of the group not measured), who received only a part of the clinician assessment. We do not consider this prevalence representative of subjects not measured.

Our population-based sample included both healthy and unhealthy persons, as they were part of the general population. Most elderly people have one or more diseases or disabilities, and completely disease-free subjects are relatively few. Furthermore, our sample included a relevant number of subjects from more widely distributed areas than previous studies on Italian elderly, providing anthropometric and health status data by means of an objective clinical evaluation.

In conclusion, we provided gender- and age-specific distributions for many anthropometric measurements for the elderly that could be used as reference values for the Italian elderly population to detect individuals at a greater risk of nutritional disorders. The association found between age and anthropometric measurements is consistent with the results of many longitudinal studies. Different anthropometric measurements (BMI, waist:hip ratio, waist circumference) showed a high prevalence of obesity for women, where the visceral fat increase seems to continue.

\section{Appendix}

The ILSA Working Group: M. Baldereschi MD, A. Di Carlo MD, S. Maggi MD (CNR; Italian National Research Council, Italy), G. Scarlato MD, L. Candelise MD, E. Scarpini MD (University of Milano, Italy), F. Grigoletto ScD, E. Perissinotto ScD, L. Battistin MD, M. Bressan MD, G. Enzi MD, G. Bortolan ScD (University of Padova, Italy), C. Loeb, MD (CNR; Italian National Research Council, Genova, Italy), C. Gandolfo MD (University of Genova, Italy), N. Canal MD, M. Franceschi, MD (San Raffaele Institute, Milano, Italy), A. Ghetti MD, R. Vergassola MD (ULS 10, Firenze, Italy), D. Inzitari, MD (University of Firenze, Italy), S. Bonaiuto MD, F. Fini MD, A. Vesprini MD, G. Cruciani MD (INRCA Fermo, Italy), A. Capurso MD, P. Livrea MD, V. Lepore MD (University of Bari, Italy), L. Motta MD, G. Carnazzo MD (University of Catania, Italy), F. Rengo MD (University of Napoli, Italy).

\section{References}

Allison DB, Gallagher D, Heo M, Pi-Sunyer FX \& Heymsfield SB (1997) Body mass index and all-cause mortality among people age 70 and over: the Longitudinal Study of Aging. International Journal of Obesity 21, 424-431.

Bannerman E, Reilly JJ, MacLennan WJ, Kirk T \& Pender F (1997) Evaluation of validity of British anthropometric reference data for assessing nutritional state of elderly people in Edinburgh: cross-sectional study. British Medical Journal 315, 338-341.

Baumgartner RN, Heymsfield SB \& Roche AF (1995a) Human body composition and the epidemiology of chronic disease. Obesity Research 3, 73-95.

Baumgartner RN, Stauber PM, McHugh D, Koehler KM \& Garry PJ (1995b) Cross-sectional age differences in body composition in persons $60+$ years of age. Journals of Gerontology. Series A, Biological Sciences and Medical Sciences 50, 307-316.

Chumlea WC \& Baumgartner R (1989) Status of anthropometry and body composition data in elderly subjects. American Journal of Clinical Nutrition 50, 1158-1166.

Chumlea WC, Roche AF \& Steinbaugh ML (1985) Estimating stature from knee height for persons 60 to 90 years of age. Journal of the American Geriatric Society 33, 116-120.

Corish CA, Flood P, Mulligan S \& Kennedy NP (2000) Apparent low frequency of undernutrition in Dublin hospital in-patients: should we review the anthropometric thresholds for clinical practice? British Journal of Nutrition 84, 325-335.

de Groot CPGM, Enzi G, Perdigao AL \& Deurenberg P (1996) Longitudinal changes in the anthropometric characteristics of elderly Europeans. Euronut Seneca Investigators. European Journal of Clinical Nutrition 50, 9-15.

de Groot CPGM, Hautvast JG \& van Staveren WA (1992) Nutrition and health of elderly people in Europe: the Euronut Seneca Study. Nutrition Reviews 50, 185-194.

de Groot CPGM, Sette S, Zajkas G, Carbajal A \& Amorim JA (1991) Nutritional status: anthropometry Euronut Seneca Investigators. European Journal of Clinical Nutrition 45, $31-42$.

de Onis M \& Habicht JP (1996) Anthropometric reference data for international use: recommendations from a World Health Organization Expert Committee. American Journal of Clinical Nutrition 64, 650-658.

Delarue J, Constans T, Malvy D, Pradignac A, Couet C \& Lamisse F (1994) Anthropometric values in an elderly French population. British Journal of Nutrition 71, 295-302.

Den Tonkelaar I, Seidell JC, Van Noord PAH, Baanders-Van Halewijn EA, Jacobus JH \& Bruning PF (1989) Factors influencing waist/hip ratio in randomly selected pre- and postmenopausal women in the Dom-Project (Preliminary Results). International Journal of Obesity 13, 817-824.

Dey DK, Rothenberg E, Sundh V, Bosaeus I \& Steen B (1999) Height and body weight in the elderly. I. A 25 year longitudinal study of a population aged 70 to 95 years. European Journal of Clinical Nutrition 53, 905-914.

Enzi G, Gasparo M, Biondetti PR, Fiore D, Semisa M \& Zurlo F (1986) Subcutaneous and visceral fat distribution according to sex, age and overweight, evaluated by computed tomography. American Journal of Clinical Nutrition 44, 739-746.

Enzi G, Sergi G, Bussolotto M, Ceccon A, Giantin V \& Benincà P (1997) Methods for quantitation of body composition, with particular reference to lean body mass. In Amino Acid and Protein Metabolism in Health and Disease, pp. 5-11 [P Tessari, PB Soeters, G Pittoni and A Tiengo, editors]. Bedford, Great Britain: Smith-Gordon.

Fanelli Kuczmarski M, Kuckzmarski R \& Najjar M (2000) Descriptive anthropometric reference data for older Americans. Journal of The American Dietetic Association 100, 59-66.

Gallagher D, Visser M, De Meersman RE, Sepulveda D, Baumgartner N, Pierson RN, Harris T \& Heymsfied SB (1997) Appendicular skeletal muscle mass: effects of age, gender, and ethnicity. Journal of Applied Physiology 83, 229-239.

Going S, Williams D \& Lohman T (1995) Aging and body composition: biological changes and methodological issues. Exercise and Sport Sciences Review 23, 411-458.

Han TS, van Leer EM, Seidell JC \& Lean MEJ (1995) Waist 
circumference action levels in the identification of cardiovascular risk factors: prevalence study in a random sample. British Medical Journal 311, 1401-1405.

Harris T, Cook EF, Garrison R, Higgins M, Kannel W \& Glodman L (1988) Body mass index and mortality among nonsmoking older persons. Journal of the American Medical Association 259, 1520-1524.

Heymsfield SB, Baumgartner RN \& Ross R (1998) Evaluation of total and regional body-composition. In Handbook of Obesity, pp. 41-47 [GA Bray, C Bouchard and WPT James, editors]. New York: M Dekker.

ISTAT (1986) Sommario di Statistiche Storiche. Istituto Centrale di Statistica (Summary of Historical Statistics. National Institute of Statistics). Rome: Chicca e C.

Jensen GL \& Rogers J (1998) Obesity in older persons. Journal of the American Dietetic Association 98, 1308-1311.

Kish L (1965) Survey Sampling. New York: John Wiley.

Kleinbaum DG, Kupper L, Muller KE \& Nizam A (1998) Applied Regression Analysis and other Multivariable Methods. Pacific Grove, CA: Duxbury Press.

Kotani K, Tokunaga K, Fujioka S, Kobatake T, Keno Y, Yoshida S, Shimomura I, Tarui S \& Matsuzawa Y (1994) Sexual dimorphism of age-related changes in whole-body fat distribution in the obese. International Journal of Obesity 18, 207-212.

Launer LJ \& Harris T (1996) Weight, height and body mass index distributions in geographically and ethnically diverse samples of older persons. Age and Ageing 25, 300-306.

Lean MEJ, Han TS \& Morrison CE (1995) Waist circumference as a measure for indicating need for weight management. British Medical Journal 311, 158-161.

McWhirter JP \& Pennington CR (1994) Incidence and recognition of malnutrition in hospital. British Medical Journal 308, 945-948.

Maggi S, Zucchetto M, Grigoletto F, Baldereschi M, Candelise L, Scarpini E, Scarlato G \& Amaducci L (1994) The Italian Longitudinal Study on Aging (ILSA): Design and methods. Aging Clinical and Experimental Research 6, 464-473.

Malina RM (1990) Research on secular trends in auxology. Anthropologischer Anzeiger; Bericht Uber Die Biologischanthropologische Literatur 48, 209-227.

Mattila K, Haavisto M \& Rajala S (1986) Body mass index and mortality in the elderly. British Medical Journal 292, 867-868.

Meadows Jantz L \& Jantz RL (1999) Secular change in long bone length and proportion in the United States, 1800-1970. American Journal of Physical Anthropology 110, 57-67.

Melchionda N, Enzi G, Caviezel F, Cairella M, Contaldo F, Gatto MRA, Babini AC, Parenti M, Pasquali R, Grassi M \& Crepaldi G (1990) Epidemiology of obesity in the elderly: CNR multicentric study in Italy. Diabetes Research and Clinical Practice 10, S11-S16.

Molarius A \& Seidell JC (1998) Selection of anthropometric indicators for classification of abdominal fatness - a critical review. International Journal of Obesity 22, 719-727.

Pouliot MC, Despres JP, Lemieux S, Moorjani S, Bouchard C, Tremblay A, Nadeau A \& Lupien PJ (1994) Waist circumference and abdominal sagittal diameter: best simple anthropometric indexes of abdominal visceral adipose tissue accumulation and related cardiovascular risk in men and women. American Journal of Cardiology 73, 460-468.

Quetelet A (1835) Sur l'Homme et le Developpement de ses Facultes, ou Essai des Physique Sociale (On Man and the Development of his Faculties, or Treatise on Social Physics). Paris: Bachelier.

Rea IM, Gillen S \& Clarke E (1997) Anthropometric measurements from a cross-sectional survey of community dwelling subjects aged over 90 years of age. European Journal of Clinical Nutrition 51, 102-106.

Schwartz R (1998) Obesity in the elderly. In Handbook of Obesity, pp. 103-114 [GA Bray, C Bouchard and WPT James, editors]. New York: M Dekker.

Seidell JC, Han TS, Feskens EJM \& Lean MEJ (1997) Narrow hips and broad waist circumferences independently contribute to increased risk of non-insulin-dependent diabetes mellitus. Journal of Internal Medicine 242, 401-406.

Seidell JC, Kahn HS, Williamson DF, Lissner L \& Valdez R (2001) Report from a Centers for Disease Control and Prevention workshop on use of adult anthropometry for public health and primary health care. American Journal of Clinical Nutrition 73, 123-126.

Seidell JC \& Visscher TLS (2000) Body weight and weight change and their health implications for elderly. European Journal of Clinical Nutrition 54, S33-S39.

Sorkin JD, Muller DC \& Andres R (1999) Longitudinal change in height of men and women: Implications for interpretation of the body mass index. American Journal of Epidemiology 150, 969-977.

Steen B (1988) Body composition and aging. Nutrition Reviews 46, $45-51$.

Stevens J, Cai J, Pamuk ER, Williamson DF, Thun MJ \& Wood JL (1998) The effect of age on the association between body-mass index and mortality. New England Journal of Medicine 338, $1-7$.

The ILSA Group (1997) Prevalence of chronic diseases in older Italians: comparing self-reported and clinical diagnoses. International Journal of Epidemiology 26, 995-1002.

Visscher TLS, Seidell JC, Menotti A, Blackburn H, Nissinen A, Feskens EJM \& Kromhout D (2000) Underweight and overweight in relation to mortality among men aged 40-59 and 50-69 years. American Journal of Epidemiology 151, 660-666.

Visser M, Langlois J, Guralnik JM, Cauley JA, Kronmal RA, Robbins J, Williamson JD \& Harris TB (1998) High body fatness, but not low fat-free mass, predicts disability in older men and women: the Cardiovascular Health Study. American Journal of Clinical Nutrition 68, 584-590.

Visser M, van den Heuvel E \& Deurenberg P (1994) Prediction equations for the estimation of body composition in the elderly using anthropometric data. British Journal of Nutrition 71, $823-833$.

WHO Expert Committee (1995) The Use and Interpretation of Anthropometry. WHO Technical Report Series no. 854. Geneva: WHO.

Zamboni M, Armellini F, Harris T, Turcato E, Micciolo R, Bergamo-Andreis IA \& Bosello O (1997) Effects of age on body fat distribution and cardiovascular risk factors in women. American Journal of Clinical Nutrition 66, 111-115. 